\title{
REPRESENTAÇÃO DA INFORMAÇÃO MUSICAL: EMOÇÕES EXPRESSAS PELOS USUÁRIOS.
}

\section{MUSIC INFORMATION REPRESENTATION: EMOTIONS EXPRESSED BY USERS}

Camila Monteiro de Barrosa

\begin{abstract}
RESUMO
Introdução: Conceitos representativos do domínio da música podem estar relacionados a diferentes dimensões: emocional, estrutural, tecnológica, etc., variando, assim, suas formas de representação para recuperação. Objetivo: Com enfoque na dimensão emocional relacionada à experiência musical do ouvinte, o presente artigo teve o objetivo de revelar os aspectos expressados pelos usuários em seus comentários a respeito de uma música específica e relacionar esses aspectos à representação da informação musical. Metodologia: Foram coletados 304 comentários postados pelos usuários do Youtube. Foram analisados idioma, extensão e forma de expressão dos comentários, presença e natureza geral de aspectos emocionais. De forma indutiva, verificamos as facetas às quais os comentários se referiam. Resultados: Os resultados apontam que as principais formas de expressão utilizadas pelos usuários foram textuais, emojis ou emoticons. Um total de $79,1 \%$ expressaram algum aspecto emocional, destes, $53,6 \%$ aspectos positivos e 13,1\% negativos. A análise indutiva demonstrou 12 facetas emocionais, contendo referências a aspectos sonoros, à emoção evocada por experiências passadas, entre outros. Conclusões: As facetas observadas representam o ponto de vista dos usuários em um tipo de classificação geral que pode ser utilizada para orientar serviços de recomendação, ser fonte de extração de termos em linguagem natural, atuarem como coadjuvantes no enriquecimento semântico de termos e expressões para recuperação da informação musical.
\end{abstract}

Descritores: Música. Representação da informação. Recuperação da informação.

\section{INTRODUÇÃO}

A música vista como fenômeno informacional traz consigo a noção de

\footnotetext{
* Resultados de uma das três etapas da pesquisa "Os níveis de significado na Organização do Conhecimento e da Informação", desenvolvida no período 2018-2019, com apoio do CNPq por meio de bolsa PIBIC da aluna Jhessika Thomaz Pereira.

a Doutora em Ciência da Informação pelo Programa de Pós-Graduação em Ciência da Informação da Universidade Federal de Santa Catarina (UFSC). Professora do Departamento de Ciência da Inforrmação e do Programa de Pós-Graduação em Ciência da Informação da Universidade Federal de Santa Catarina (UFSC). E-mail: camila.c.m.b@ufsc.br
} 
reflexividade em que ocorre um "processo contínuo e recíproco em que humanos exercem influência sobre seus contextos e os contextos influenciam os humanos" (WEISSENBERGER, 2015, p. 918, tradução nossa'1). Essa característica não é única da música, mas talvez se mostre de forma mais acentuada do que na informação verbal ou imagética, já que "a música, [...] dada sua grande fragilidade referencial, é compensada por seu enorme poder evocador" (SANTAELLA, 2009, p. 109). É necessário aproximarmos essa noção de reflexividade à Organização do Conhecimento $(\mathrm{OC})$, colocando a representação da informação musical no âmbito de completude representacional relativa (MCLANE, 1996). Isto é, uma representação mais ou menos completa é avaliada conforme se vislumbra sua implicação na recuperação da informação musical. Em outras palavras, a completude da representação da informação musical varia substancialmente dependendo da finalidade a que serve, como por exemplo, recuperação de música específica, recomendação de músicas para manutenção do perfil musical do usuário, descoberta de músicas novas, entre outras.

Nesse sentido, também cada dimensão da informação terá serventia distinta. De acordo com Gnoli (2012), o fenômeno informacional pode ser compreendido em seis dimensões:

\section{Figura 1 - Dimensões do fenômeno informacional}

\begin{tabular}{|l|l|l|}
\hline$\alpha$ & (reality) & [mystique?] \\
\hline$\beta$ & phenomena & [ontology] \\
\hline$\gamma$ & perspectives & [epistemology] \\
\hline$\delta$ & carriers & [bibliology] \\
\hline$\varepsilon$ & collections & [library science] \\
\hline$\zeta$ & users & [sociology] \\
\hline
\end{tabular}

Fonte: Gnoli (2012, p. 270)

Destas, o autor dá especial atenção à dimensão do "fenômeno percebido" (ontologia) como a mais elementar dos estudos da OC, seguida da dimensão que abrange as diferentes perspectivas em relação à "interpretação do fenômeno" (epistemologia). A dimensão "documental” (bibliologia) é considerada

\footnotetext{
1 "the ongoing, reciprocal process where humans exert influence upon their contexts and contexts influence humans" (WEISSENBERGER, 2015, p. 918).
} 
por Gnoli (2012) como menos central, porém, pode alcançar grande relevância quando o domínio de conhecimento a ser representado tem a formalidade documental como característica (como é o caso da comunicação científica).

Com relação à dimensão do fenômeno percebido, nos aproximamos da perspectiva fenomenológica, ou seja, a realidade como se apresenta, porém mutável em função do processo perceptivo (PEIRCE, 1995). Nesse viés fenomenológico da percepção, a construção de significado recai sobre a experiência do ouvinte, ou seja, a mesma música pode causar ou evocar diferentes compreensões do mesmo fenômeno. Diversos estudos já apontaram a relevância da experiência do ouvinte para o desvelamento de termos passíveis de representarem a música para fins de classificação e recuperação. (FONT; SERRÀ; SERRA, 2015; LAPLANTE, 2010, 2011, 2015, LEE; DOWNIE, 2004, LEE, 2010, CRUZ et al., 2011). Isso significa afirmar que nem todos os aspectos que compõem o conjunto de elementos descritivos da informação musical encontram-se na própria informação musical de forma passiva.

É fato que a representação desse tipo de informação exige input humano (VAN DE LAAR, 2006), que pode ser maior (como no caso da definição de emoções relacionadas à música) ou menor (como no caso da definição de autoria), dependendo da finalidade da representação. De qualquer forma, a experiência do ouvinte só pode ser acessada por meio do autorrelato, por meio da vontade individual de compartilhar os significados associados à música. $\mathrm{O}$ acesso a essas informações é possível por meio de redes sociais que permitam a interação ativa do usuário, seja por meio de comentários de texto, de registro de "likes", do uso de emojis ${ }^{2}$ ou emoticons, etc.

Considerando essas questões particulares da representação da informação musical, o objetivo deste artigo é revelar quais são os aspectos expressados pelos usuários em comentários registrados em plataformas colaborativas no que se refere às suas experiências, com especial atenção à expressão de emoções. Também procuramos desvendar que indicações esses

\footnotetext{
2 De acordo com a Wikipedia (2019), emojis são imagens usadas em mensagens eletrônicas, incluindo expressões faciais, objetos, lugares, animais e tipos de clima, como " $O$ " e ". Já os emoticons são sequências de caracteres tipográficos que expressam algum sentimento, como :) e : .
} 
aspectos podem fornecer à área de organização do conhecimento nas discussões sobre representação da informação musical.

\section{O USUÁRIO NO PROCESSO DE REPRESENTAÇÃO DA INFORMAÇÃO MUSICAL}

De acordo com Brascher e Café (2010), a Organização do Conhecimento (OC) se volta ao mapeamento conceitual de domínios de conhecimento, cujo resultado desse processo é a Representação do Conhecimento (RC). Tal representação é por sua vez utilizada na atividade de representação de conteúdo de informações que, juntamente com outros processos, compõe a Organização da informação (OI). O produto da OI é o conjunto de elementos descritivos da informação, ou seja, é a Representação da Informação (RI).

Os elementos descritivos da informação têm como função facilitar sua recuperação, bem como fornecer subsídios para que o usuário possa decidir a respeito da relevância das informações recuperadas. No caso da música, entretanto, a noção de descrição de "conteúdo" não é clara, já que, excetuandose as informações relacionadas à catalogação, as demais características apresentam naturezas distintas entre si, não cabendo a designação única de uma categoria de "assunto". A definição do gênero musical, da emoção ou situação associada à música, a popularidade do artista intérprete, são exemplos de descrição que podem influenciar a escolha do usuário no momento de decidir o que ouvir e quando.

Laplante (2010) explora de que forma características intra e extramusicais influenciam o julgamento de relevância dos jovens na busca por músicas para fins de recreação. Considerando a natureza subjetiva da noção de relevância, na coleta dos dados a autora realizou entrevistas em profundidade. Os resultados da pesquisa mostram que o contexto específico de uso é um aspecto fundamental para que os usuários atribuam relevância a um item. Esse aspecto é evidenciado pelos usuários quando afirmam a necessidade de ouvir o áudio antes de decidir por sua pertinência, caracterizando a centralidade do conjunto de aspectos que constituem a experiência individual do usuário. Não obstante, a autora sinaliza também a relevância das informações bibliográficas referentes à 
produção musical.

Em Laplante (2011), a autora dá continuidade ao estudo do comportamento dos usuários e retoma, nos resultados da sua pesquisa, a forte influência do contexto social na seleção de músicas. Consideramos a popularidade das redes sociais, que se confirmam como espaço de convivência, relações e troca de experiências, a autora aponta que os jovens se interessam mais pela representatividade social (atitudes, valores, etc.) de grupos de jovens que escutam certo gênero musical do que com a música em si. Nesse caso, o gênero musical representa aquilo com o qual o usuário quer se parecer, se aproximar.

Nesse sentido, Zangerle e Pichl (2018) afirmam que as preferências musicais dos usuários não podem ser avaliadas com base na média do seu comportamento de escuta. Os autores defendem que é necessário considerar distintos conjuntos de preferências, dependendo de aspectos contextuais. Tal medida poderia capturar melhor o comportamento do usuário, aprimorando sistemas de busca e recomendação de músicas.

Em uma discussão voltada para a esfera aplicada, Lee e Downie (2004) e Lee (2010) expõem que os estudos de usuários devem ser a base para o desenvolvimento de qualquer sistema de recuperação da informação musical (RIM). Ou seja, não é possível fazer afirmações a priori sobre as características necessárias de um sistema desse tipo, tampouco a natureza dos elementos de descrição da música sem que se tenha um perfil consolidado das necessidades dos usuários.

Os estudos envolvendo usuários da informação musical trazem resultados que mostram a recorrente interferência de ambientes colaborativos (redes sociais e relações pessoais) no consumo da música. Também apontam a necessidade de acesso à informação por meio de características que vão além da descrição bibliográfica e têm dependência do contexto do usuário (LAPLANTE, 2010, 2011; LEE; DOWNIE, 2004; LEE; DOWNIE; CUNNINGHAM, 2005; LEE, 2010).

Lesaffre et al. (2008) defendem que, de forma geral, o uso da linguagem textual na representação da informação musical tem uma função social eficiente 
na exposição de forma mais objetiva daquilo que os autores chamam de "descritores semânticos", ou seja, o que é experienciado. Entretanto, é evidente que tais apreciações são expostas por termos não menos ambíguos do que a própria experiência. Além disso, atualmente sabe-se que a utilização de imagens para representar significados é uma forma de comunicação largamente adotada, tanto por aqueles que oferecem serviços de informação quanto pelos próprios usuários.

Para os autores, é difícil identificar e mapear regularidades nas relações entre as descrições fornecidas pelos usuários e o background dos usuários. Lesaffre et al. (2008), entretanto, afirmam que existem fortes relações entre "descritores de avaliação" (como agressivo/calmo) e "descritores relacionados à sonoridade" (leve/pesado, por exemplo). Também Hu e Downie (2007) por meio da análise de coocorrências de recomendações de uso feitas por usuários a um grupo de músicas, encontraram consistências nas relações estabelecidas entre emoção/gênero musical e emoção/artista, enquanto $\mathrm{Hu}$, Downie e Ehmann (2006), apontam pelo menos duas supercategorias de uso: "Ativo/Estimulante" e "Passivo/Relaxante".

Lee e Cunningham (2013) atestam que a área de RIM se desenvolveu principalmente em torno dos estudos de usuários, classificados em dois tipos: os estudos de usuários (por exemplo: necessidades de informação musical) e os estudos que envolvem usuários (como o teste de aplicações de RIM). Em amplo levantamento, os autores mostram que é a partir do ano 2000 que esses estudos têm um crescimento mais acelerado, porém, grande parte deles é realizada em pequenas escalas, dificultado qualquer generalização, sendo que dos 198 estudos analisados pelos autores, apenas 22 envolviam mais de 100 indivíduos. Além disso, a problemática do compartilhamento de resultados de pesquisa, conforme Futrelle e Downie (2002) já haviam abordado, reaparece na pesquisa de Lee e Cunningham (2013), quando relatam que tiveram que realizar o levantamento em diversos recursos de áreas distintas para obter um corpus de análise significativo. Isso atesta a pulverização das publicações - dada a natureza interdisciplinar da área e a quantidade de espaços disponíveis para publicação -, dificultando a comunicação entre pesquisadores. 
De forma mais geral, trata-se do inevitável e necessário agrupamento de conhecimentos de áreas diversas que, em suas respectivas especialidades, podem proceder à discussão e ao possível esclarecimento da miríade de conceitos envolvidos no estudo da música como informação. Esses conceitos vão desde a teoria musical, musicologia e etnomusicologia, perpassam pelo estudo de usuários, $\mathrm{OC}$ e Ol e ainda se juntam a conceitos advindos dos estudos da computação, arquitetura da informação, engenharia acústica, entre outros.

\section{EMOÇÃO E INFORMAÇÃO MUSICAL}

Com relação à emoção, estudos envolvendo usuários podem mostrar, por exemplo, se existe diferença entre as emoções induzidas pela música e as projetadas pelo ouvinte, quais as emoções mais comumente direcionadas à música e de que forma essas emoções são direcionadas à música (por exemplo, direcionadas à banda, ao som em $\mathrm{si}$, aos instrumentos musicais, etc.).

Esse e outros paradigmas que envolvem 0 uso da emoção como característica da música são apresentados por Van de Laar (2006), cuja pesquisa compara seis métodos de detecção de emoção. Esse estudo se concentra na área da tecnologia e aborda como cada algoritmo utiliza características estruturais (como batidas por minuto (bpm), frequência medida em Hertz, altura e variação de tom, etc.) e as relaciona a um rótulo que indique uma emoção. Desse estudo, podemos extrair três conclusões que nos parecem mais relevantes.

Primeiro, a eficiência de uma aplicação desse tipo depende do contexto de uso, da finalidade da aplicação. O segundo aspecto que podemos apontar é a importância da rotulagem do gênero musical que, segundo Van de Laar (2006), aumenta a precisão na detecção automática da emoção. O que chama atenção aqui é que adentramos em outra discussão igualmente pertinente e desafiadora que é a definição do gênero musical. Segundo o autor, a maior parte dos sistemas de detecção de emoções e de recomendação de músicas importam a classificação de gênero musical e os dados bibliográficos das bandas e artistas construídos por outros sistemas que se dedicam unicamente a esse fim, ou por 
outros sites na web, como o MusicBrainz³.

O terceiro aspecto é que Van de Laar (2006) nos leva a concluir que qualquer sistema de detecção de emoção precisa, necessariamente, dar espaço para a participação do input humano, seja com a participação do usuário, seja por profissionais. Conforme o autor destaca, em geral, não é aconselhável transferir toda a responsabilidade de rotulagem da emoção para o usuário, pois esse não é seu primeiro interesse, mas sim, buscar/recuperar/utilizar a música para algum fim. Entretanto, a avaliação humana é o que confere o princípio fundamental para aprendizagem do sistema (SPECK et al., 2011), já que a emoção é um fenômeno humano, subjetivo e intersubjetivo e que, até o presente momento, não pode ser completamente avaliada somente pelo computador.

Com base em pesquisa bibliográfica, Juslin e Laukka (2004) apresentam um diagrama que mostra possíveis relações entre a) emoções comumente provocadas no dia a dia, b) emoções comumente expressadas na música, c) emoções comumente provocadas pela música. Embora algumas coincidam, as emoções de cada categoria são, na sua maior parte diferentes.

A pesquisa de Juslin e Laukka (2004) também contou com a participação de 141 ouvintes não especialistas, que responderam a um questionário a respeito da indução da emoção, da percepção da emoção e da relação entre percepção e indução. Das emoções mais suscitadas pela música, os autores chegaram ao resultado de 15 termos que, segundo eles, expressariam uma escala para a medição da emoção experienciada. Com esses resultados, dois objetivos seriam alcançados: primeiro, oferecer parâmetros para descrição, análise e comparação de emoções e, segundo, enfatizar como pode ser diversa a experiência emocional provocada pela música. Conforme apontam Juslin e Laukka (2004), é preciso cuidado quando da exclusão a priori de possíveis emoções.

Há décadas estudos vêm tentando realizar o mapeamento das emoções tipicamente associadas à música, com base em diversos modelos provindos da Psicologia e utilizados na área da Psicologia da Música que, conforme Sloboda (2011), vem crescendo rapidamente nas últimas décadas, especialmente no que

\footnotetext{
${ }^{3}$ Disponível em: http://musicbrainz.org/.
} 
se refere às experiências musicais cotidianas. Alguns exemplos são o modelo circumplexo de Russel (1980), a análise relacional biopsicológica da emoção, proposta por Tayer (1989), o mapa semântico de Tellegen, Watson e Clark (1999), e o modelo de Hevner (1936) organizado especificamente para a pesquisa em música. As funções sociais da música definidas por Merriam (1964) também foram referência para estudos sobre etnomusicologia e psicologia da música em uma abordagem behaviorista. Merriam (1964) elaborou uma lista de 10 categorias das funções sociais da música: 1) expressão emocional; 2) prazer estético; 3) divertimento, entretenimento; 4) comunicação; 5) representação simbólica; 6) reação física; 7) imposição de conformidade às normas sociais; 8) validação das instituições sociais e dos rituais religiosos; 9) contribuição para a continuidade e estabilidade da cultura; 10) contribuição para a integração da sociedade.

Em revisão realizada por Laplante (2008), a autora conclui que as principais funções da música são: 1) construir identidade pessoal, 2) gerenciar o estado mental (mood), 3) trazer memórias à tona, 4) estabelecer e/ou manter relações interpessoais, 5) sugerir o comportamento adequado, 6) passar o tempo, aliviar a monotonia, 7) auxiliar a concentração/pensamento. Entretanto, sabe-se que, para que a música exerça tais funções de forma eficaz, a associação afetiva que o usuário confere à música é fundamental e é construída com base nas experiências que o usuário tem. Assim, experiências regulares e repetitivas tendem a estabilizar certas associações.

Por outro lado, quando o usuário emprega menos envolvimento com a experiência musical, esta ganha contornos diferentes. Sloboda (2011) sistematizou, em 10 afirmações, questões-chave relacionadas a emoções que incidem e interagem com a experiência musical cotidiana ordinária, das quais apresentamos um resumo: emoções cotidianas relacionadas à música tendem a ser de baixa intensidade; são breves e múltiplas, ao invés de integradas e continuadas; são mais autorreferentes (sentir-se alegre, ansioso) do que referentes a outros (por exemplo, sentir orgulho de, aprovação de); refletem e são influenciadas pelo significado emocional pessoal do contexto não musical; são suscitadas pelo autorrelato retrospectivo; são mais focadas no ouvinte do 
que na obra musical; surgem de aspectos transitórios, relacionados ao alcance de um objetivo ao qual a música é associada, ao invés de atitudes avaliativas estáveis relacionadas à música.

O objetivo de Sloboda (2011) é acentuar os contrastes entre as respostas emocionais que ocorrem na experiência musical cotidiana e aquelas que ocorrem em momentos em que o indivíduo se põe especificamente a escutar música, como em um concerto, por exemplo.

Na busca em conciliar representação de emoções relacionadas à música, objetividade e manutenção da individualidade desse tipo de referência, $\mathrm{Hu}$, Li e $\mathrm{Ng}$ (2018) sugerem o uso do mapeamento dos sinais fisiológicos dos usuários (como batimentos cardíacos), relacionando-os com a emoção autorrelatada. Os autores relatam que diferenças significativas foram observadas entre os sinais fisiológicos causados por emoções positivas e negativas. Entretanto, a classificação da música por emoção com base nesses mesmos sinais fisiológicos teve resultados positivos apenas em alguns casos particulares.

A maior parte dos estudos aqui apresentados são escritos em inglês e percebemos que os termos emotion (emoção) e mood (em tradução livre, estado mental, humor) não têm definições universalmente aceitas. Konecni (2011) e Denora (2011) sugerem que, enquanto o mood tem duração mais longa e intensidade flutuante, a emoção é mais pontual no tempo e na intensidade. Da mesma forma, o que define emoções mais ou menos complexas, as diferenças entre sentimentos e sensações, também não está definido na área de RIM. De fato, essa questão parece interessar mais à área da Psicologia e não nos aprofundaremos nela.

Sabemos, no entanto, que o uso de certos recursos aumenta a probabilidade de que a emoção expressa na música alcance o ouvinte. Conforme explicam Juslin e Laukka (2004), esses recursos podem estar mais próximos do papel do compositor - envolvendo associações entre o andamento da música e o movimento da fala, indicando momentos de tensão, raiva, alegria, etc. -, ou da ambiência criada pelo performer. Esse último se torna ainda mais eficiente quando pensamos na própria voz do cantor que, naturalmente, remete o ouvinte ao código da fala (JUSLIN; LAUKKA, 2004). Em pesquisa apresentada por 
Parada-Cabaleiro et al. (2018), os autores atestam que, em diferentes condições acústicas (ao vivo, em ambiente fechado, ao ar livre, gravação de má ou boa qualidade), a mesma música pode provocar diferentes emoções. Tal diferença foi observada pelos autores tanto na classificação automática da música quanto àquela realizada por humanos. Para Panda, Malheiro e Paiva (2018) o estudo da textura e expressividade musical para detecção de emoção constitui uma lacuna na área de RIM, quando em comparação com os estudos estruturais da música.

\section{MÉTODO}

Essa pesquisa tem caráter teórico, exploratório e aplica análise qualitativa de dados. Para este estudo, selecionamos a música "Scar Tissue" da banda "Red Hot Chilli Peppers", que apresenta as seguintes condições: a) vídeo clipe oficial disponível de forma aberta no site Youtube, b) alto número de visualizações no site e, c) gênero musical popular de forma a caracterizar, possivelmente, público mais heterogêneo.

Foram coletados 304 comentários com relação ao vídeo clipe da música postados pelos usuários do Youtube, totalizando mais de 4000 palavras. A coleta foi realizada em fevereiro de 2019, iniciando-se pelo comentário mais recente. Foram incluídos até três comentários que fossem resposta a um comentário principal.

Os dados foram analisados e categorizados manualmente de forma dedutiva de acordo com: a) Expressão ou não de significado de nível emocional; b) Forma de expressão da emoção (imagens, palavras, emojis, emoticons ${ }^{3}$, etc.); c) Expressão de emoções positivas ou negativas; d) Extensão dos comentários; e) Idioma dos comentários, conforme tabela de idiomas disponibilizada pela Agência Brasileira do ISBN ${ }^{4}$, cujas siglas estão de acordo com a norma ISO 639.

De forma indutiva, foram categorizadas, manualmente, as facetas emocionais expressas pelos usuários, resultando em 12 facetas conforme resultados a seguir.

\footnotetext{
${ }^{4}$ Disponível em: http://www.isbn.bn.br/website/tabela-de-idiomas
} 


\section{RESULTADOS}

Serão apresentados a seguir gráficos referentes aos dados coletados, primeiramente com relação à análise dedutiva e, posteriormente, com relação à análise indutiva.

Dentre os 304 comentários, 92\% (282) utilizam texto como principal forma de expressão sendo que destes, 19 misturam o conteúdo textual a emojis ou emoticons. Em 14 comentários (5\%) observamos a utilização de somente emojis ou emoticons. Apenas quatro dos comentários coletados utilizam outra forma, como links para outros conteúdos.

O gráfico 1 mostra o idioma dos comentários analisados.

\section{Gráfico 1 - Idioma dos comentários}

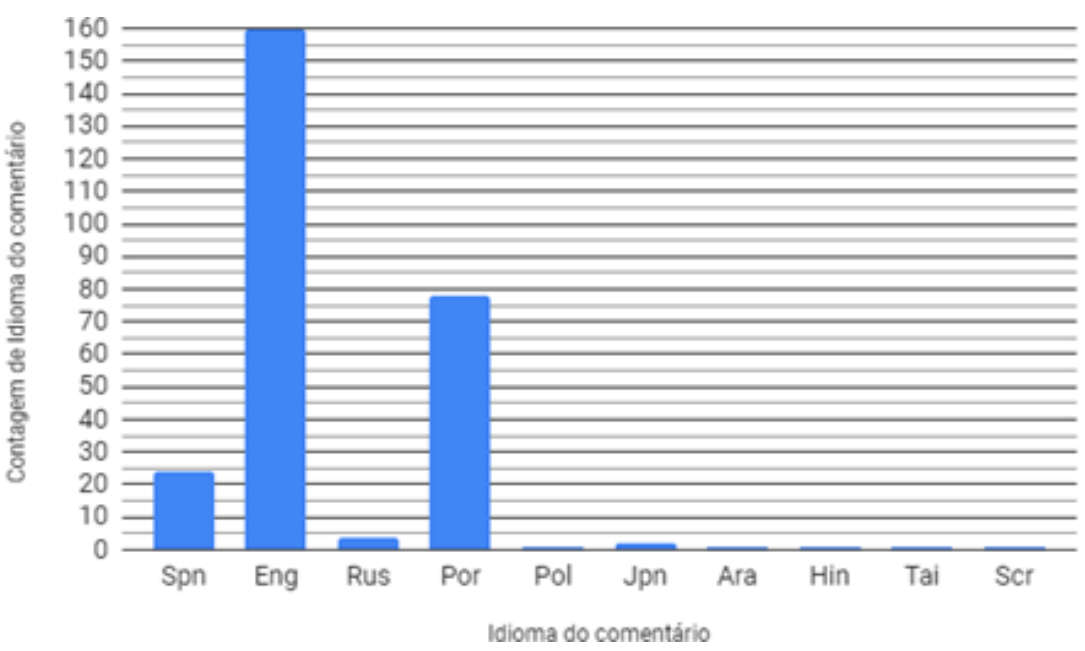

Fonte: Dados da pesquisa, 2019.

Pôde-se visualizar a grande incidência de comentários em inglês e em português, o que remete ao interesse e participação de brasileiros no contexto e conteúdo musical da banda de natureza norte americana. É relevante ressaltar que do montante da coleta, 34 comentários apresentavam somente figuras ou números, não sendo possível definir um idioma.

Mais de 230 comentários (79\%) expressava algum tipo de emoção, conforme. Os comentários que expressam aspectos emocionais são aqueles que possuem, por exemplo, emojis relacionados a sentimentos, como:

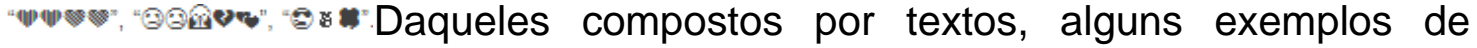
expressão de emoção são: "Música Liinda q marcou minha adolescência amo 
demais essa Banda Red Hot chilli peppers pra sempre", "Amo esta canción, siempre que voy en carretera la llevo en la mente" (comentário em espanhol que significa, em tradução livre, "Eu amo essa música, sempre que pego a estrada a levo na minha mente"), "When i listen to this i imagine myself flying in the clouds" (comentário em inglês que significa, em tradução livre, "Quando eu escuto isso, eu me imagino voando nas nuvens"), entre outros.

Comentários que expressam emoções, contudo, não possuem como tema central a própria informação musical, como por exemplo: “¿Quien dio dislike? Algún sordo de mierda seguro oi reggaetonero" (comentário em espanhol que significa, em tradução livre, "Quem deu dislike? Alguns surdos de merda com certeza ou reggaetoneros"). Este comentário traz um aspecto emocional de desgosto por aqueles que deram "dislike" no vídeo.

Comentários classificados por não expressarem eventuais aspectos emocionais, são aqueles com informações diversas, com ou sem vínculo com a informação musical, questionamentos, emojis que parecem não expressar emoções, comentários com a letra da música na íntegra, etc. Alguns exemplos de comentários sem aspectos emocionais: "ஐت", "2020?", "Alguém em 2077 aqui em Marte ????, "2018 BR", "The drummer looks so much like Will Ferrel" (comentário em inglês que significa, em tradução livre, "O baterista se parece muito com Will Ferrell"), “'Alguien de Trujillo? 2018” (comentário em espanhol que significa, em tradução livre, "Alguém de Trujillo? 2018"), "0:14 a 0:20 subliminar illuminati?' (comentário em inglês que faz referência a dois trechos do clipe, indagando se os mesmos fazem menção a mensagens subliminares Illuminati).

Os comentários que apresentavam aspectos emocionais foram classificados de acordo com a natureza da emoção expressada (gráfico 2). A maior parte dos comentários (163) apresentavam aspectos emocionais positivos.

\section{Gráfico 2 - Tipo de emoção expressada}




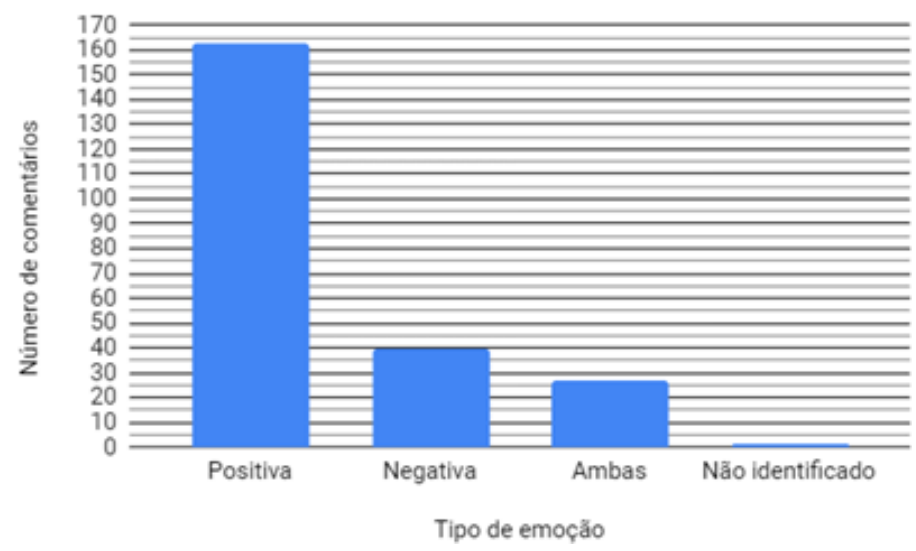

Fonte: Dados da pesquisa, 2019.

Foram considerados comentários que apresentam emoções de natureza positiva, aqueles que remetem a bons sentimentos, como alegria, amor, entusiasmo, lembranças boas, etc. Alguns exemplos de comentários positivos são: "Ah os solos do John! Guitarra que pariu, que show do caramba!", "Always time listening up-to 20500" (comentário em inglês que significa, em tradução livre, “A todo tempo ouvindo até 20500”), “いい曲だねえ” (comentário em japonês que significa, em tradução livre, "É uma boa música"), "amo esta cancion!!!!!!" (comentário em espanhol que significa, em tradução livre, "amo essa música!!!!!!”), “Vibe Positiva com essa trilha * * entre outros.

Foram considerados comentários que apresentam emoções de natureza negativa, aqueles que remetem a sentimentos ruins, como nostalgia, tristeza, medo, raiva, etc. Podem ser considerados negativos os comentários: "Am I the only one who thinks the lyrics are creepy asf, like just read em out loud to yourself and tell me they don't seem really off [...] words have 2 meanings and this one has some pretty sinister connections if you look into real occult shit... [...]" (comentário em inglês que expressa, de maneira resumida, o medo do usuário quanto ao significado da letra da música, o mesmo parece acreditar que a letra traz mensagens ocultas), "I miss those times_-2), (comentário em inglês que significa, em tradução livre, "Eu sinto falta desses momentos"), "terry dowling 1 second ago Google --red hot chili peppers sexual misconduct BS!!! I hate when bad people sing sensitive lyrics and assault women and lie about it!" (comentário em inglês que expressa, de maneira resumida, o repúdio de um usuário em relação a um integrante da banda "quando pessoas más cantam músicas 
sensíveis e agridem mulheres e mentem sobre isso", provavelmente devido ao fato deste ter estado envolvido em um caso de abuso sexual), "my best friend is moving away and my life is over" (comentário em inglês que significa, em tradução livre, "minha melhor amiga está se afastando e minha vida acabou"), entre outros.

Foram considerados comentários que possui ambas as emoções, natureza positiva e negativa, aqueles que remetem a ambos sentimentos de maneira mais ou menos explícita, como por exemplo: "Música top, infelizmente meu país e uma merda e $n$ tem cultura :(“ (observamos nestes comentários a presença explícita de dois sentimento, um bom, com relação a música e um ruim com relação ao país de origem do usuário), "Another good one that reminds me of you David Ruiz. Fuck I miss youl | I know your now resting and watching over us. [...] Rest in paradise Love (David Ruiz) 6/9/75-8/8/18 (19)ev (comentário em inglês que sugere um sentimento de tristeza e nostalgia, contudo, ao mesmo tempo, de maneira implícita, um sentimento de amor.)

Não foi possível identificar a existência de aspectos emocionais em 12 comentários. Estes comentários não apresentavam informações suficientes para sua interpretação ou são providos de expressões muito particulares que dificultam seu entendimento. Exemplos de comentário neste parâmetro são os composto somente por símbolos:

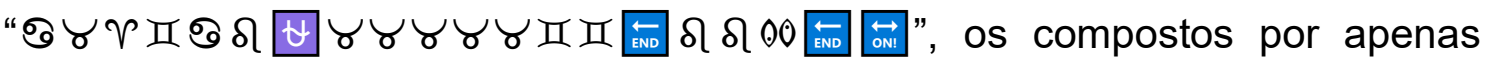
uma palavra que é desprovida de significado quando utilizada isoladamente, como por exemplo, a conjunção "que", a repetição excessiva de letras ou palavras desconhecidas como por exemplo: "Cac@aaaaaaaaaaaaaaaaaaaaaaaaaaaaaaaaaaaaaaaaaaaaaa".

Conforme evidenciado anteriormente, existem particularidades na representação da informação musical que são exteriorizadas pela subjetividade das expressões dos usuários, fãs ou ouvintes, que estão atreladas às suas emoções. Da mesma forma, tal subjetividade não é menor quando da interpretação dessas expressões para fins de pesquisa. Dessa forma, necessariamente a análise desse tipo de dado carrega consigo certo grau de parcialidade quando da sua classificação. A natureza do aspecto emocional 
expressado nos conteúdos resultou em 12 facetas emocionais: experiência, banda, som, emoção, outros conteúdos, letra, letra/emoção, outras músicas, clipe, país (de origem), outros países e outros, como consta no gráfico a seguir:

\section{Gráfico 3 - Teor do conteúdo emocional dos comentários}

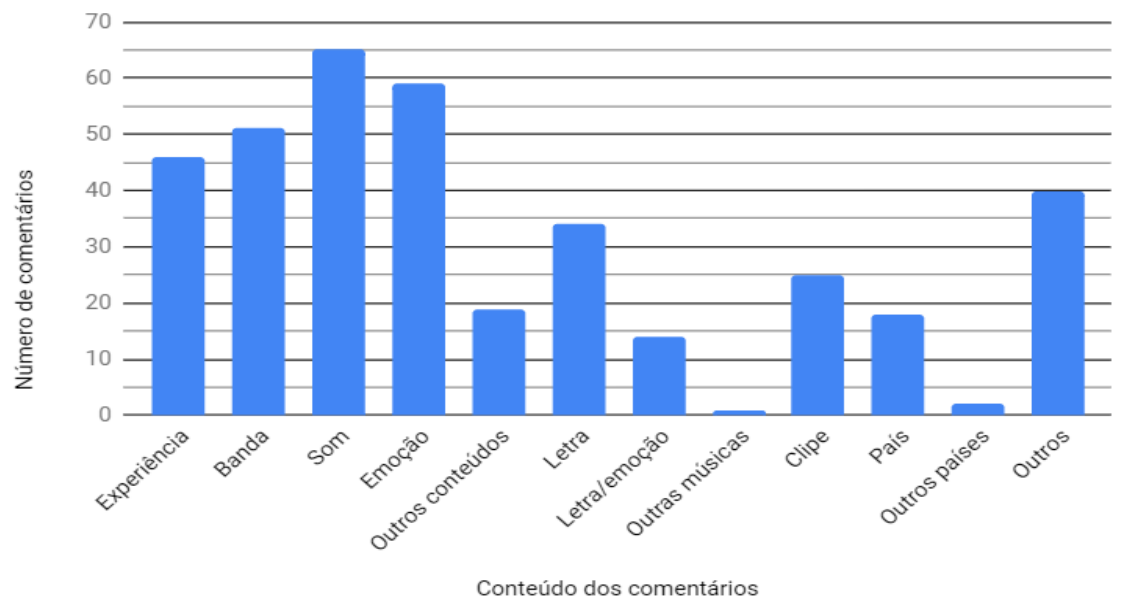

Fonte: Dados da pesquisa, 2019.

Os comentários categorizados como "experiência" são aqueles que remetem a momentos passados vividos pelo usuário (lembranças, familiares, amigos), situações corriqueiras (ouço essa música quando...), ou momentos para os quais essa música seria uma perfeita trilha sonora, como por exemplo, "Reminders me of a person that had to take my heart away for his own but to never give it back and this song says all of what my feelings are and hits hard too. Thank you for making an amazing song to help me,get through my hell. You rock XOXOXO" (comentário em inglês que remete à lembrança de uma pessoa que o usuário precisou "tirar de seu coração"), "Minha banda favorita, fez parte da minha infância e adolescência! $\boldsymbol{\bigotimes}_{B R}$ ", "One of my high school anthem songs...walking the halls...not giving a fuck, belting this song out!" (comentário em inglês cuja tradução livre é "Uma das minhas canções do hino do ensino médio ... andando pelos corredores ... não dando a mínima, cantando essa música!"), "Escuto sempre essa música quando estou de ressaca", "This is my song to listen to while im in hospital. I hear it often" (comentário em inglês cuja tradução livre é "Esta é a minha música para ouvir enquanto estou no hospital. Eu ouço isso frequentemente"), "Domingo cedinho a caminho da praia «", entre 
outros.

Os comentários categorizados como "banda" são aqueles que se referem à aparência física, atitudes, valores, curiosidades, etc, dos membros da banda, como por exemplo: "Esses cara são muito bom", "That broken guitar simbolize the hard life John haved left behind his back, however broken, still nice and worthed.throw away Ur suffering and keep going on" (comentário em inglês se referindo ao guitarrista da banda, em tradução livre: "Aquela guitarra quebrada simboliza a vida dura que John deixou para trás, por mais quebrada, ainda boa e digna [...]", "Amo dms esses cara ৫๑”, entre outros.

Os comentários categorizados como "som" são aqueles que expressam algo sobre a melodia e/ou os instrumentos que compõem a música, como por exemplo: "Increible la viola en este tema!!!" (comentário em espanhol cuja a tradução livre é "Violão incrível nesse tema!!!"), "That final solo is fucking amazing..." (comentário em inglês cuja a tradução livre é "Esse solo final é f* incrível ..."), "Genial,buena musica,bonito sonido,y mas me gusta el sonido de la guitarra :D", (comentário em espanhol cuja a tradução livre é "Ótima, boa música, bom som e eu gosto do som da guitarra: D"), entre outros.

Os comentários categorizados como "emoção" são aqueles relacionados a alguma emoção suscitada pela música, como: "I wish my brother who passed Mike secanti was still here" (comentário em inglês cuja a tradução livre é "Eu queria que meu irmão que passou por Mike Secanti ainda estivesse aqui", um sentimento implícito de saudade),"<3<3<3" (provável sentimento de amor, alegria...), "this relaxes me to the bone" (comentário em inglês cuja a tradução livre é "Isso me relaxa até o osso", sugerindo sentimento de calma), "Anyone else listen to it when there sad" (comentário em inglês cuja a tradução livre é "Alguém mais ouve quando está triste".

Os comentários categorizados como "outros conteúdos" são aqueles que fazem referência a outros assuntos, como outros artistas, outros textos, links para outros conteúdos, etc., como por exemplo: “Listen to my new Red Hot Chili Peppers Remix: The Other side ! https://youtu.be/2R1aUk4tU6Y" (comentário em inglês cuja a tradução livre é "Ouça o meu novo remix Red Hot Chili Peppers: O outro lado [...]), "www.youtube.com/watch?v=nqsz7U1rojs" (um link para outro 
conteúdo), "Tema de Tati e Rodrigo em uma temporada de malhação" (referência a personagens de uma novela), "Who's here because of Camila Cabello?' (comentário em inglês cuja a tradução é "Quem está aqui por causa de Camila Cabello?", referência a uma cantora da atualidade que já cantou essa música).

Os comentários categorizados como "letra" são aqueles que reproduzem a letra na íntegra, a tradução da letra na íntegra ou ainda correções, observações de gramática, estilo, etc. Já os comentários categorizados como "letra/emoção" são aqueles relacionados ao significado de trechos específicos da letra, como por exemplo: "He battled heroin addiction lost his first guitarist to heroin addiction and the one with the solo had just gotten back from rehab. It's about all that pain," (comentário em inglês cuja tradução livre é: "Ele lutou contra o vício em heroína, perdeu seu primeiro guitarrista para o vício em heroína e aquele com o solo tinha acabado de voltar da reabilitação. É sobre toda essa dor"), "To me this song is talking about a person hitting another with that gun \{needle\}......Scar tissue $i$ wish u saw...Mr no it all...\{the guy in the back that knows all\} but cant hit u...close ur eyes and ill kiss $u\{$ ounce $u$ hit them there yours\}.....BAMMMMM...Listen closely ....to the moon....lonely view.....blood lost.....push up bra.....euphoria ......speek softley with Broken jaw....Imao.....when $u$ can not talk after the shot.........hahahaha hahahaha....bath room stall... wave goob buy to maw and paw......and it is a lonley view" (comentário em inglês em que o usuário parece tentar desvendar o significado de determinadas estrofes da música).

Os comentários categorizados como "outras músicas", são aqueles que fazem referência a outras canções, como por exemplo: "Hj em dia tenho que escutar "deixa eu cutucar seu boga"kkkkk", "Fuck despacito".

Os comentários categorizados como "clipe", são aqueles que se referem a imagens, momentos, conteúdos e assuntos relacionados ao clipe, como por exemplo: "no guitars were harmed during the making of this video" (comentário em inglês cuja tradução livre é "Nenhuma guitarra foi prejudicada durante a produção deste vídeo"), "Anybody know where is the location of this video shooting...?? Look so awesome...!!!" (comentário em inglês cuja a tradução livre é "Alguém sabe onde é a localização da filmagem deste vídeo ... ?? Parece tão incrível ...!!!"). 
Dos comentários que expressavam algo relacionado ao país de origem do usuário, foram observados tanto comentários de cunho negativo como positivo. Como por exemplo: "Melhor banda do mundo viva red hot, viva Brasil!!!!!!" "Aqui é Br 2018 ROCK É VIDA", "Só da Br nessa porra!! kk", "Música top, infelizmente meu país e uma merda e $\mathrm{n}$ tem cultura". Os comentários categorizados como "outros países", se referem aos usuários de um determinado país, que comentam a respeito de outro país, como por exemplo, "Brazilians have good taste in rock music" (comentário em inglês cuja tradução livre é "Os brasileiros têm bom gosto pra rock"), "pq tantos br y 0 argentinos escuchando musica d verdad" (comentário em espanhol cuja tradução livre é "pq tantos br e 0 argentinos ouvindo música d verdade") "Como eu queria ser um norte-americano são os melhores em tudo".

Os comentários categorizados como "outros" não possuem relação com nenhuma das categorias anteriores, como por exemplo, "DAM THOSE DIET COMMERCIALS! Hey U Ppl working in Youtube shd know better than to do those kinds of agravaiting diet commercials that w/o excepting, or clicking anytng you ram them down our throat! [...]) Now I'm on a crappy mood![...]" (comentário em inglês, no qual o usuário critica comerciais de dieta).

É importante destacar que a maioria dos comentários traz mais de uma das categorizações citadas, já que, obviamente as categorias não são excludentes e refletem a própria complexidade da análise desse tipo de dados.

\section{CONCLUSÃO}

Os resultados mostram a alta recorrência de aspectos emocionais nas expressões referentes à informação musical, fato que evidencia a centralidade deste tipo de característica para os usuários, quando da utilização de um serviço de informação como o Youtube.

Os conteúdos dos comentários com teor emocional resultaram naquilo que nomeamos "12 facetas emocionais". Sendo oriundas de análise indutiva de um grupo limitado de dados, essas facetas representam uma das possíveis formas da área de OC olhar para esse tipo de conjunto de dados e pensar formas de torná-los semanticamente ricos para fins de representação da informação. As facetas podem funcionar, por exemplo, como um tipo de classificação inicial a 
ser utilizada em serviços de recomendação de música ou ainda fonte de extração de termos representativos do domínio da música, do ponto de vista dos usuários.

Como já comentamos anteriormente, as expressões relacionadas à emoção podem ser tanto ou mais ambíguas que o próprio conceito de emoção, fato que, inevitavelmente, fica claro quando da análise dos dados. Por outro lado, os dados mostram facetas mais objetivas, como referência à letra da música, imagens do clipe e países (de origem do ouvinte ou não). O compartilhamento desse tipo de expressão indica a vontade própria do usuário em expor sua opinião a esse respeito, sendo, portanto, informação relevante nesse ambiente. Em situação hipotética, as facetas "Países" e "Outros países" poderiam sustentar uma classificação gerando uma playlist como "O que os brasileiros estão ouvindo/comentando", ou algo similar.

O elevado número de comentários que se referiam ao próprio som indica que aspectos da dimensão sonora da música são destaque na percepção dos ouvintes sobre sua experiência musical. Entre as inúmeras pesquisas sobre classificação automática da música com base no processamento do som, parece que os comentários dos ouvintes podem servir de base para a definição de que parâmetros devem ser considerados quando em um contexto de serviços como - Youtube: evolução harmônica; extensão de solos de guitarra, baixo, etc., textura (mais grave, mais agudo), entre outros. Também verificamos a intertextualidade que pode ser visualizada nas tentativas dos usuários de decifrar o significado da letra da música, do contexto dos acontecimentos no clipe, misturando-os à melodia e outras expressões.

De fato, o vocabulário que representa cada faceta precisa ser refinado, comparado, desenvolvido. Da mesma forma, é preciso pensar estratégias para o processamento dos comentários. O recorrente uso de gírias, adaptações gramaticais, mistura de idiomas, figuras, etc., podem dificultar o processamento automático da linguagem natural. Importante ressaltar que é preciso preservar o espaço de livre expressão do usuário e que suas necessidades, no contexto da informação musical, estão mais atreladas à revocação que à precisão. Aqui, o refinamento dos métodos de captura desse tipo de informação aparece como possibilidade de estudo futuro. 
Parece ser evidente a relevância de os sistemas de RIM disponibilizarem um rico conjunto de elementos que possibilitem uma rede de relações entre músicas e artistas e que incluam comentários de usuários com julgamentos e recomendações de outras músicas. Isso significa dizer que, dada a natureza subjetiva da percepção fruto da experiência musical, é preciso estabelecer um espaço na descrição da informação musical para que tais experiências sejam compartilhadas. Talvez não com o fim último de recuperação de um item, mas como forma de apoiar o usuário na descoberta de músicas ou manutenção de seu perfil musical.

\section{REFERÊNCIAS}

BRÄSCHER, M.; CAFÉ, L. Organização da Informação ou Organização do Conhecimento? In: LARA, M. L. G. de; SMIT, J. W. (Org.) Temas de Pesquisa em Ciência da Informação no Brasil. São Paulo: Escola de Comunicação e Artes/USP, 2010. p. 87-103.

CRUZ, F. W.; CUNHA, M. B.; FERNEDA, E.; ALONSO, L. B. N.; VASCONCELOS, A. M. N. Um modelo para mapeamento de necessidades e usos de informação musical. Perspectivas em Ciência da Informação, Belo Horizonte, v. 16, n. 2, p. 207-227, abr./jun. 2011. Disponível em: http://www.scielo.br/pdf/pci/v16n2/13.pdf. Acesso em: 24 abr. 2016.

DENORA, T. Emotion as social emergence: perspectives from musicology. In: JUSLIN, P. N.; SLOBODA, J. A. Handbook of music and emotion: theory, research, applications. Oxford: Oxford University Press, 2011.

FONT, F.; SERRÀ, J.; SERRA, X. Analysis of the impact of a tag recommendation system in a real-world folksonomy. ACM Transactions on Intelligent Systems and Technology, v. 7, n. 1, 2015.

FUTRELLE, J., DOWNIE, J. S. Interdisciplinary communities and research issues in music information retrieval. In: INTERNATIONAL SOCIETY FOR MUSIC INFORMATION RETRIEVAL CONFERENCE, Paris, 2002. Anais [...], Paris, 2002. Disponível em: http://ismir2002.ismir.net/proceedings/02-FP073.pdf. Acesso em: 23 jan. 2014.

GNOLI, C. Metadata about what? Distinguishing between ontic, epistemic, and documental dimensions in knowledge organization. Knowledge Organization, v. 39, n. 4, p. 268-275, 2012.

HEVNER, K. Experimental studies of the elements of expression in music source. The American Journal of Psychology, v. 48, n. 2. p. 246-268, abr. 
1936. Disponível em:

https://www.jstor.org/stable/1415746?seq=1\#page_scan_tab_contents. Acesso em: 17 jan. 2019.

HU, X.; DOWNIE, J. S.; EHMANN, A. F. Exploiting recommended usage metadata: exploratory analyses. In: INTERNATIONAL SOCIETY FOR MUSIC INFORMATION RETRIEVAL CONFERENCE, Victoria, 2006. Anais [...], Victoria, 2006. Disponível em:

https://static.aminer.org/pdf/PDF/000/439/595/exploiting_recommended_usage _metadata_exploratory_analyses.pdf. Acesso em: 22 out. 2020.

HU, X.; DOWNIE, J. S. Exploring mood metadata: relationships with genre, artist and usage metadata. In: INTERNATIONAL SOCIETY FOR MUSIC INFORMATION RETRIEVAL CONFERENCE, Viena, 2007. Anais [...], Viena, 2007. Disponível em:

http://ismir2007.ismir.net/proceedings/ISMIR2007_p067_hu.pdf. Acesso em: 08 set. 2010.

HU, X.; LI, F.; NG, J. T. D. On the relationship between music-induced emotion and physiological signals. In: INTERNATIONAL SOCIETY FOR MUSIC INFORMATION RETRIEVAL CONFERENCE, 19, Paris, 2018. Anais [...], Paris (FR), 2018. Disponível em: ismir2018.ircam.fr/doc/pdfs/115_Paper.pdf. Acesso em:23 jan. 2019.

JUSLIN, P. N.; LAUKKA, P. Expression, perception, and induction of musical emotions: a review and a questionnaire study of everyday listening. Journal of New Music Research, v. 33, n. 3, p. 217-238, 2004.

KONECNI, V. J. The influence of affect on music choice. In: JUSLIN, P. N.; SLOBODA, J. A. Handbook of music and emotion: theory, research, applications. Oxford: Oxford University Press, 2011. p.697-724.

\section{LAPLANTE, A. Everyday life music information-seeking behaviour of}

young adults: an exploratory study. 2008, $332 \mathrm{f}$. Tese (Doctor of Philosophy) McGill University, School of Information Studies, Faculty of Education, Montréal (Canadá), 2008. Disponível em:

https://escholarship.mcgill.ca/concern/theses/2514np20z. Acesso em: 22 out. 2020.

LAPLANTE, A. Users' Relevance Criteria in Music Retrieval in Everyday Life: An Exploratory Study. In: INTERNATIONAL SOCIETY FOR MUSIC INFORMATION RETRIEVAL CONFERENCE, 11, Utrecht, 2010. Anais [...], Utrecht, 2010, p. 601-606. Disponível em:

http://ismir2010.ismir.net/proceedings/ismir2010-103.pdf. Acesso em: 15 jun. 2014.

LAPLANTE, A. Social capital and music discovery: an examination of the ties through which late adolescents discover new music. In: INTERNATIONAL SOCIETY FOR MUSIC INFORMATION RETRIEVAL CONFERENCE, 12, 
Miami, 2011. Anais [...], Miami, 2011, p. 341-346. Disponível em: http://ismir2011.ismir.net/papers/OS5-2.pdf. Acesso em: 15 jun. 2014.

LAPLANTE, Audrey. Tagged at first listen: an examination of social tagging practices in a music recommender system. Encontros Bibli, Florianópolis, v. 20, n. 1, p. 33-54, 2015. Disponível em: https://www.redalyc.org/pdf/147/14735377004.pdf. Acesso em: 27 out. 2020.

LEE, J. H. Analysis of user needs and information features in natural language queries seeking music information. Journal of the American Society for Information Science and Technology, v. 61, n. 5, p. 1025-1045, 2010.

LEE, J. H.; CUNNINGHAM, S. J. Toward an understanding of the history and impact of user studies in music information retrieval. Journal of Intelligent Information Systems, v. 41, n. 3, p. 499-521, 2013.

LEE, J. H.; DOWNIE, J. S.; CUNNINGHAM, S. J. Challenges in crosscultural/multilingual music information seeking. In: INTERNATIONAL SOCIETY FOR MUSIC INFORMATION RETRIEVAL CONFERENCE, 6, London, 2005. Anais [...], London, 2005, p. 1-7. Disponível em: http://ismir2005.ismir.net/proceedings/1100.pdf. Acesso em: 22 jan. 2014

LEE, J. H.; DOWNIE, J. S. Survey of music information needs, uses, and seeking behaviours: preliminary findings. In: INTERNATIONAL SOCIETY FOR MUSIC INFORMATION RETRIEVAL CONFERENCE, 5, Barcelona, 2004.

Anais [...], Disponível em: https://www.semanticscholar.org/paper/Survey-OfMusic-Information-Needs\%2C-Uses\%2C-And-Lee-

Downie/38dd11 deaadd13d2c21904ae2bdf9789f6cfbbbb. Acesso em: 22 jan. 2014.

LESAFFRE, M.; DE VOOGDT, L.; LEMAN, M.; DE BAETS, B.; DE MEYER, H.; MARTENS, J. How potencial users of music search and retrieval systems describe the semantic quality of music. Journal of the American Society for Information Science and Technology, v. 59, n. 5, p. 695- 707, 2008.

MCLANE, A. Music as information. In: CRONIN, B. ANNUAL REVIEW OF INFORMATION SCIENCE AND TECHNOLOGY, Anais [...], 37. ed. Medford: Information Today, p. 295-340, 1996.

MERRIAM, A. P. The anthropology of music. Evanston: Northwestern University Press, 1964.

PANDA, R.; MALHEIRO, R.; PAIVA, R. P. Musical Texture and Expressivity Features for Music Emotion Recognition. In: INTERNATIONAL SOCIETY FOR MUSIC INFORMATION RETRIEVAL CONFERENCE, 19, Paris, 2018. Anais [...], Paris, 2018. Disponível em: http://ismir2018.ircam.fr/doc/pdfs/250_Paper.pdf. Acesso em: 27 out. 2020. 
PARADA-CABALEIRO, E.; SCHMITT, M.; BATLINER, A.; HANTKE, S.; COSTANTINI, G.; SCHERER, K.; SCHULLER, B. W. Identifying emotions in opera singing: implications of adverse acoustic conditions. In: INTERNATIONAL SOCIETY FOR MUSIC INFORMATION RETRIEVAL CONFERENCE, 19, Paris, 2018. Anais [...], Paris, 2018. Disponível em: http://ismir2018.ircam.fr/doc/pdfs/22_Paper.pdf. Acesso em: 23 jan. 2019.

PEIRCE, C. S. Semiótica. 3. ed. São Paulo: Perspectiva, 1995.

RUSSELL, J. A. A circumplex model of affect. Journal of Personality and Social Psychology, v. 39, n. 6, p. 1161-1178, 1980.

SANTAELLA, L. Matrizes da linguagem e pensamento: sonora, visual, verbal: aplicações na hipermídia. 3. ed. São Paulo: lluminuras; FAPESP, 2009.

SLOBODA, J. A. Music in everyday life: the role of emotions. In: JUSLIN, P. N.; SLOBODA, J. A. (Orgs.) Handbook of music and emotion: theory, research, applications. Oxford: Oxford University Press, 2011.

SPECK, J. A.; SCHMIDT, E. M.; MORTON, B. G.; KIM, Y. E. A comparative study of collaborative vs. traditional musical mood annotation. In:

INTERNATIONAL SOCIETY FOR MUSIC INFORMATION RETRIEVAL CONFERENCE, 12, Miami, 2011. Anais [...], Miami, 2004. Disponível em: http://www.mirlab.org/conference_papers/International_Conference/ISMIR\%202 011/papers/PS4-13.pdf. Acesso em: 23 out. 2015.

TELLEGEN, A.; WATSON, D.; CLARK, L. A. On the Dimensional and Hierarchical Structure of Affect. Psychological Science, v. 10, n. 4. p. 297303, Jul./1999.

THAYER, R. E. The biopsychology of mood and arousal. New York: Oxford University Press, 1989.

VAN DE LAAR, B. Emotion detection in music, a survey. In: TWENTH STUDENT CONFERENCE ON IT, 4, Enschede, 2006. Anais [...], Enschede, 2006. Disponível em:

https://citeseerx.ist.psu.edu/viewdoc/download?doi=10.1.1.75.284\&rep=rep1\&ty pe=pdf. Acesso em: 22 out. 2020.

WEISSENBERGER, L. Toward a universal, meta-theoretical framework for music information classification and retrieval. Journal of Documentation, $v$. 71, n. 5, p. 917-937, 2015.

WIKIPEDIA. Emoji. Disponível em: https://pt.wikipedia.org/wiki/Emoji. Acesso em: 23 jan. 2019.

ZANGERLE, E.; PICHL, M. Content-based user models: modeling the many faces of musical preference. In: INTERNATIONAL SOCIETY FOR MUSIC INFORMATION RETRIEVAL CONFERENCE, Paris, 2018. Anais [...], Paris 

em: 23 jan. 2019.

\title{
MUSIC INFORMATION REPRESENTATION: EMOTIONS EXPRESSED BY USERS
}

\begin{abstract}
Introduction: Representative concepts of music information domain are related to many dimensions: emotional, structural, technological, etc., varying its representation forms for retrieval purposes. Objective: Focusing on the emotional dimension related to listeners' musical experiences, the goal of this paper was to reveal the aspects expressed by the users in their comments about a specific song and video clip, and to relate these aspects with music information representation field. Methodology: We collected 304 comments from Youtube and we analyzed language, extension and expression forms, presence and nature of the expressed emotional aspects. Inductively, we verified the facets to which comments were referring to. Results: The main forms of expression used by users were textual, emojis or emoticons. A total of $79,1 \%$ of comments expressed some emotional aspect, being $53,6 \%$ positives and $13,1 \%$ negatives. Inductive analysis resulted in 12 emotional facets, referring to sound aspects, emotions evoked by past experiences, among others. Conclusions: The facets represent the user point of view in a way of general classification that can be used to guide recommendation systems, be a source of extraction of natural language terms, acting as supporting to enrich semantically terms and expressions for music information retrieval.
\end{abstract}

Descriptors: Music. Information representation. Information retrieval.

\section{REPRESENTACIÓN DE LA INFORMACIÓN MUSICAL: EMOCIONES EXPRESADAS POR LOS USUARIOS}

\begin{abstract}
RESUMEN
Introducción: Conceptos representativos del dominio de la música pueden relacionarse con distintas dimensiones: emocional, estructural, tecnológica, entre otros, variando, así, sus formas de representación para recuperación. Objetivo: Con atención en la dimensión emocional relacionada a la experiencia musical del oyente, el presente artículo tiene el objetivo de revelar los aspectos expresados por los usuarios en sus comentarios acerca de una música específica y relacionar estos aspectos a la representación de la información musical. Metodología: Fueron recogidos 304 comentarios publicados por los usuarios del sitio Youtube. Fueron analizados idioma, extensión y forma de expresión, así como la presencia y naturaleza general de los aspectos emocionales. Por inducción, verificamos las facetas por las cuales se refieren los comentarios. Resultados: Los resultados apuntan que las principales formas de expresión utilizadas por los usuarios fueran textuales, emojis o emoticonos. Un total de $79,1 \%$ han expresado algún aspecto emocional, de estos, $53,6 \%$ aspectos positivos y $13,1 \%$ negativos. La análisis inductiva ha demostrado 12 facetas emocionales, que contiene referencias a aspectos sonoros, la emoción evocada por experiencias pasadas, entre otros. Conclusiones: Las facetas observadas representan el punto de vista de los usuarios en cierto tipo de clasificación general que puede ser utilizada para
\end{abstract}

Inf. Inf., Londrina, v. 25, n. 3, p. $306-331$, jul./set. 2020. 
orientar servicios de recomendación, ser origen de extracción de términos en lenguaje natural, que actúen como auxiliares en el enriquecimiento semántico de los términos y expresiones para la recuperación de la información musical.

Descriptores: Información Musical. Representación de la Información. Recuperación de la Información.

Recebido em: 15/09/2020

Aceito em: 30/09/2020 